\title{
Rapid Increase of Gastrointestinal P-Glycoprotein Functional Activity in Response to Etoposide Stimulation
}

\author{
Kentaro Yano, ${ }^{*, a, b}$ Masaki Kimura, ${ }^{b}$ Yayoi Watanabe, ${ }^{b}$ and Takuo Ogihara ${ }^{c}$ \\ ${ }^{a}$ Laboratory of Drug Metabolism and Pharmacokinetics, Yokohama University of Pharmacy; 601 Matano-cho, \\ Totsuka-ku, Yokohama 245-0066, Japan: ${ }^{b}$ Laboratory of Biopharmaceutics, Department of Pharmacology, Takasaki \\ University of Health and Welfare; 60 Nakaorui-machi, Takasaki, Gunma 370-0033, Japan: and ${ }^{c}$ Laboratory of \\ Clinical Pharmacokinetics, Graduate School of Pharmaceutical Sciences, Takasaki University of Health and Welfare; \\ 60 Nakaorui-machi, Takasaki, Gunma 370-0033, Japan.
}

Received January 4, 2021; accepted February 23, 2021

\begin{abstract}
We previously reported that exposure of human colon adenocarcinoma (Caco-2) cells to the bitter substance phenylthiocarbamide (PTC) rapidly enhanced the transport function of P-glycoprotein (P-gp). In this study, we investigated the short-term effect of etoposide, another bitter-tasting P-gp substrate, on P-gp transport function in the same cell line. We found that etoposide exposure significantly increased both the P-gp protein level in the plasma membrane fraction and the efflux rate of rhodamine123 (Rho123) in Caco-2 cells within $10 \mathrm{~min}$. The efflux ratio (ratio of the apparent permeability coefficient in the basal-to-apical direction to that in the apical-to-basal direction) of Rho123 in etoposide-treated cells was also significantly increased compared with the control. These results indicated that etoposide rapidly enhances P-gp function in Caco-2 cells. In contrast, P-gp expression in whole cells at both the mRNA and protein level was unchanged by etoposide exposure, compared with the levels in non-treated cells. Furthermore, etoposide increased the level of phosphorylated ezrin, radixin and moesin (P-ERM) proteins in the plasma membrane fraction of Caco-2 cells within $10 \mathrm{~min}$. P-gp functional changes were blocked by YM022, an inhibitor of cholecystokinin (CCK) receptor. These results suggest that etoposide induces release of $\mathrm{CCK}$, causing activation of the CCK receptor followed by phosphorylation of ERM proteins, which recruit intracellular P-gp for trafficking to the gastrointestinal membrane, thereby increasing the functional activity of P-gp.
\end{abstract}

Key words P-glycoprotein (P-gp); etoposide; ezrin radixin moesin (ERM) protein; human colon adenocarcinoma (Caco-2) cell; membrane localization; cholecystokinin

\section{INTRODUCTION}

P-Glycoprotein (P-gp) is an ATP-dependent efflux pump whose functional activity is regulated by the scaffold proteins ezrin, radixin and moesin (ERM), which mediate trafficking of P-gp to the plasma membrane and hold it in place there. ${ }^{1-3)}$ In the digestive tract, P-gp prevents the entry of toxic substances and drugs into the body. ${ }^{4,5)}$ Such toxic compounds frequently taste bitter, and bitterness is sensed by taste receptor type 2 (T2R), which is expressed not only in the oral cavity, but also in epithelial cells of the digestive tract. ${ }^{6}$ We have previously reported that P-gp substrates often exhibit strong bitterness, and this characteristic can be used to predict whether drug candidates are likely to be P-gp substrates.7) Furthermore, we found that exposure of human colon adenocarcinoma (Caco-2) cells, a human gastrointestinal epithelial cell model, to the bitter-tasting substance phenylthiocarbamide (PTC) rapidly (within $90 \mathrm{~min}$ ) enhanced the transport function of $\mathrm{P}-\mathrm{gp}^{8}$ due to an increase of P-gp membrane expression mediated by the activation of ERM proteins via stimulation of the gastrointestinal hormone cholecystokinin-8 (CCK-8) receptor. This is consistent with the idea that the body recognizes potentially harmful bitter substances in the digestive tract and enhances the function of P-gp by secreting gastrointestinal hormones, in order to block entry of the substances into the body., ${ }^{9,10)}$ However, there is little information as to whether clinically used bitter-tasting drugs can rapidly enhance P-gp function through this mechanism. We reported that etoposide, a bitter-tasting oral anticancer drug, is a P-gp substrate,,$^{7)}$ and other researchers have shown that exposure to this drug for several days results in an increase in the membrane localization of ERM proteins and P-gp in mouse small intestine. ${ }^{11,12)}$ Moreover, it was reported that a 9h PTC exposure in Caco-2 cells and mice intestine increased P-gp mRNA, leading to an increase of P-gp functional activity. ${ }^{13)}$ Therefore, in this study, we investigated the short-term effect of etoposide on P-gp transport function and its mechanism in order to clarify whether etoposide can rapidly enhance the transport function of P-gp.

\section{MATERIALS AND METHODS}

Chemicals Rhodamine123 (Rho123) and etoposide were purchased from Sigma-Aldrich Inc. (St. Louis, MO, U.S.A.) and FUJIFILM Wako Pure Chemical Corporation (Osaka, Japan), respectively. Other reagents were of analytical grade.

Cell Culture Caco-2 cells were cultured in Dulbecco's modified Eagle's medium (DMEM) with high glucose (FUJIFILM Wako Pure Chemical Corporation) containing 100 units penicillin- $100 \mu \mathrm{g}$ streptomycin, nonessential amino acids (Thermo Fisher Scientific, MA, U.S.A.), and 10\% fetal bovine serum at $37^{\circ} \mathrm{C}$ in a humidified atmosphere of $5 \%$ $\mathrm{CO}_{2}-95 \%$ air. Caco-2 cells were cultured as described above in the culture medium. For efflux assay and preparation of homogenate and plasma membrane, Caco-2 cells were plated at a density of $1.0 \times 10^{5}$ cells/well on BioLite 24-well and 6-well multidishes respectively and cultured for $7 \mathrm{~d}$. To evaluate the 
bidirectional transport of Rho123, which is a P-gp substrate, Caco- 2 cells were seeded at a density of $1.26 \times 10^{5}$ cells/well on Transwell ${ }^{\circledR} 12$-well plates and cultured for $21 \mathrm{~d}$.

Preparation of Homogenate and Plasma Membrane, and Western Blotting Analysis The homogenate and plasma membrane proteins were extracted using a Minute Plasma Membrane Protein Isolation Kit (Invent Biotechnologies, Eden Prairie, MN, U.S.A.) according to the manufacturer's protocol. Briefly, cells were homogenized in buffer A using an ultrasonic disruptor (Tomy Seiko, Tokyo, Japan). To prepare plasma membrane fraction, a part of the homogenate was transferred to a filter cartridge and centrifuged at $16000 \times \boldsymbol{g}$ for $30 \mathrm{~s}$. The supernatant was further centrifuged at $16000 \times \boldsymbol{g}$ for $10 \mathrm{~min}$. The pellet was suspended in buffer B, and centrifuged at $7800 \times \boldsymbol{g}$ for $5 \mathrm{~min}$. The supernatant was then centrifuged again at $16000 \times \boldsymbol{g}$ for $30 \mathrm{~min}$, and the pellet was collected as the plasma membrane (PM) fraction. The protein concentrations of homogenate and PM samples were determined using the Lowry method. Aliquots of each fraction ( $35 \mu \mathrm{g}$ protein/lane) were subjected to Western blotting analysis as described previously. ${ }^{14)}$

RT Quantitative (q)PCR The total RNA of Caco-2 cells was isolated using ISOGEN $^{\circledR}$ (Nippon Gene, Toyama, Japan), followed by synthesis of the cDNA using a HighCapacity Complementary DNA Reverse Transcription Kit (Applied Biosystems, Foster City, CA, U.S.A.) in accordance with the manufacturer's protocol. The target mRNA in cDNA samples was amplified by using THUNDERBIRD ${ }^{\mathrm{TM}}$ qPCR Mix (Toyobo, Osaka, Japan). Expression levels of mRNA were calculated using the delta-delta $\mathrm{Ct}$ method, in which the amount of target mRNA is normalized to that of glyceraldehyde-3-phosphate dehydrogenase (GAPDH). The sequences of primer pairs for P-gp and GAPDH were as follows: P-gp (forward, 5'-TGG TCA GTG TTGATGGACAGG-3'; reverse, 5'-ACA TTT TCA CGGCCA TAGCG-3'), GAPDH (forward, 5'-AGA TCA TCA GCA ATG CCT CC-3'; reverse, 5'-TGT GGT CAT GAG TCC TTC CA-3').

The specificity was checked by analyzing the melting curves and by agarose gel electrophoresis.

Efflux Assay The efflux rate of Rho123 was evaluated using the same method as described in our previous reports with some modifications. ${ }^{15)}$ Caco-2 cells were pretreated with or without $10 \mu \mathrm{M}$ YM022 for $2 \mathrm{~h}$, followed by washing twice

A

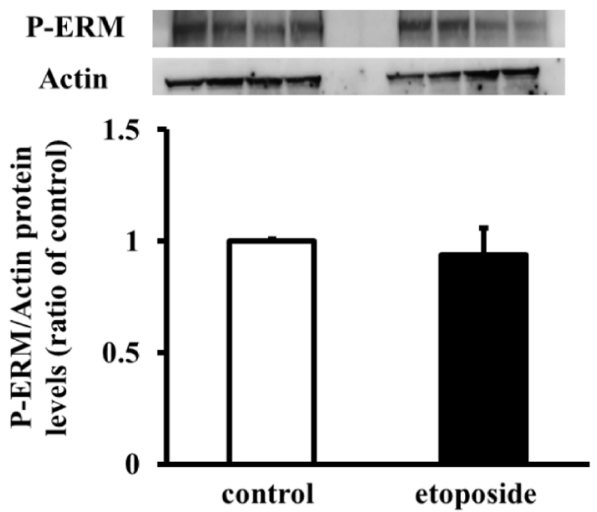

with ice-cold phosphate-buffered saline (PBS) and treatment with or without etoposide in ice-cold Opti-MEM for $10 \mathrm{~min}$. Next, cells were incubated with $10 \mu \mathrm{M}$ Rhol 23 for $30 \mathrm{~min}$, and then washed twice with ice-cold PBS again. Efflux of Rho123 from the cells to the medium was evaluated during incubation in Opti-MEM at $37^{\circ} \mathrm{C}$ for $10 \mathrm{~min}$. To stop the assay, cells were washed with ice-cold PBS. Initial uptake of Rho123 in cells was measured after preincubation for $10 \mathrm{~min}$.

Transport Study To assess P-gp-mediated transport, bidirectional transport studies were conducted using Rho123 with or without etoposide and YM022 in Caco-2 cell monolayers. The apical side (A) and the basal side (B) of a Transwell ${ }^{\circledR}$ were filled with $0.5 \mathrm{~mL}$ Hanks' balanced salt solution (HBSS) with 2-[N-morpholino]ethanesulfonic acid (MES) (pH 6.5) and $1.5 \mathrm{~mL}$ HBSS-4-[2-hydroxyethyl]-1-piperazineethanesulfonic acid (HEPES) ( $\mathrm{pH} 7.4)$, respectively. The buffer with or without $10 \mu \mathrm{M}$ YM022 was added to the basal side for $2 \mathrm{~h}$ before etoposide treatment, as previously described. ${ }^{8)}$ The apical and basal solutions contained $10 \mu \mathrm{M}$ Rho123 with or without $100 \mu \mathrm{M}$ etoposide, while blank HBSS was added to the receiving chamber. At 15 and $30 \mathrm{~min}$ from the start of the test, $100 \mu \mathrm{L}$ aliquots was taken from the receiving chamber, and an equal volume of HBSS was added.

Calculation of Efflux Rate and Efflux Ratio of Rho123 After efflux assay and transport study, Rho123 in samples was determined by measuring the fluorescence intensity using a WALLAC Multilabel/Luminescence Counter (PerkinElmer, Inc., Waltham, MA, U.S.A.) at wavelengths of $485 \mathrm{~nm}$ (excitation) and $538 \mathrm{~nm}$ (emission). Protein concentration was measured via the Lowry method. The efflux rate was calculated using the following formula:

$$
\begin{aligned}
& X_{0}=\frac{\text { initial uptake of Rho1 } 23(\mu \mathrm{M})}{\text { protein concentration }(\mathrm{g} / \mathrm{L})} \\
& X_{10}=\frac{\text { Rho123 concentration after incubation at } 37^{\circ} \mathrm{C}(\mu \mathrm{M})}{\text { protein concentration }(\mathrm{g} / \mathrm{L})}
\end{aligned}
$$

Efflux rate (nmol/min/g protein)

$$
=\frac{\left(X_{0}-X_{10}\right)}{\text { incubation time at } 37^{\circ} \mathrm{C}(\min )}
$$

The efflux ratio was obtained from the apparent apical-tobasal $\left(P_{\text {app, A to B }}\right)$ and basal-to-apical $\left(P_{\text {app, B to A }}\right)$ permeability

B

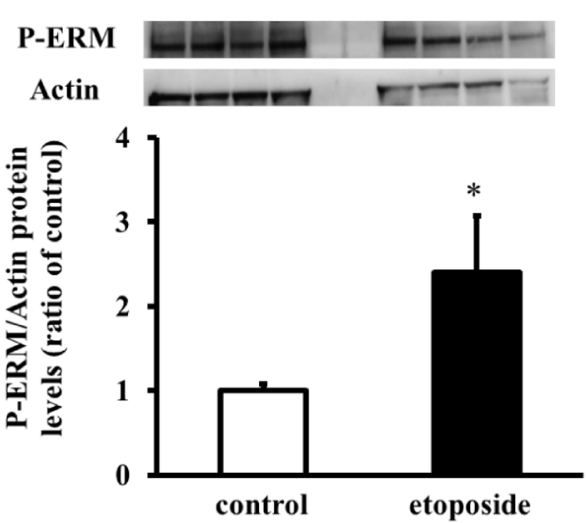

Fig. 1. Effect of Etoposide on the Intracellular Localization of P-ERM Proteins

Open and closed bars indicate control and etoposide-treated cells, respectively. P-ERM protein levels in the homogenate (A) and in the plasma membrane fraction (B) were normalized to actin in each fraction. Each sample was loaded in quadruplicate lanes. Molecular markers were loaded in two lanes between the control and etoposidetreated cells. Results are mean \pm standard error (S.E.) $(n=4-8)$. $* p<0.05$. 
A

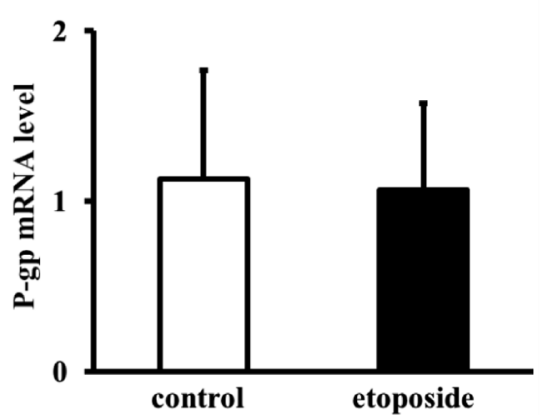

B

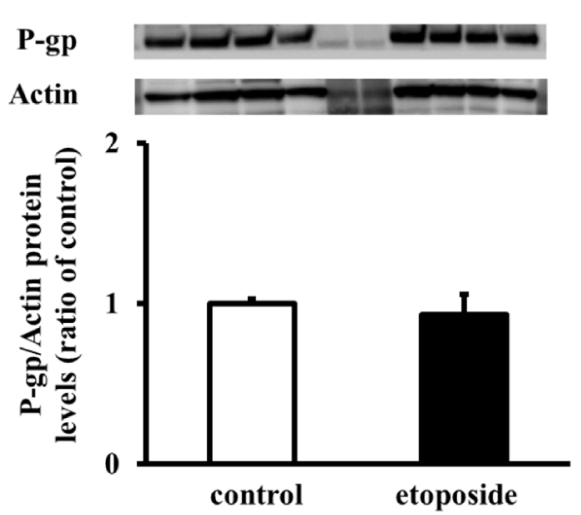

C

Plasma Membrane
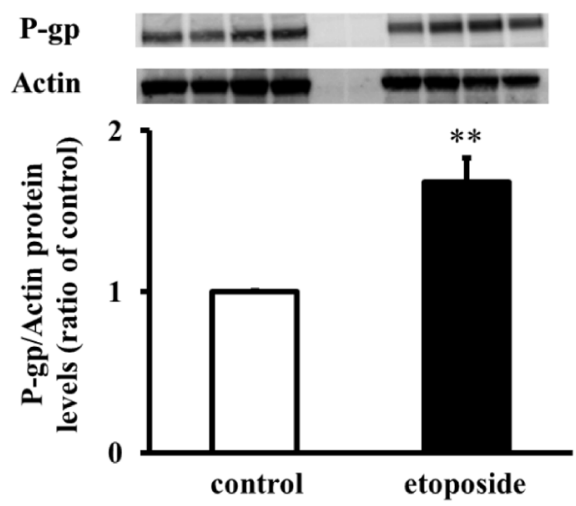

Fig. 2. Effect of Etoposide on P-gp mRNA Levels and Intracellular Localization of P-gp

Open and closed bars indicate control and etoposide-treated cells, respectively. (A) mRNA expression levels of P-gp were normalized to GAPDH. Results are mean \pm CV $(n=4-5) .{ }^{*} p<0.05$. P-gp protein levels in the homogenate (B) and in the plasma membrane fraction (C) were normalized to actin in each fraction. Each sample was loaded in quadruplicate lanes. Molecular markers were loaded in two lanes between the control and etoposide-treated cells. Results are mean \pm S.E. $(n=5-7)$. $* *<0.01$.

coefficients, which were calculated from the amounts of drugs that appeared on the receiver side per second.

$$
\text { Efflux ratio }=P_{\text {app, B to A }} / P_{\text {app, A to B }}
$$

Statistical Analysis Data are shown as means \pm standard error (S.E.). Statistical comparisons were made by means of Student's $t$-test and Tukey's test. Values of $p<0.05$ or 0.01 were considered significant.

\section{RESULTS}

Effect of Etoposide on Phosphorylated Ezrin, Radixin and Moesin (P-ERM) Protein Levels and Intracellular Localization P-ERM protein expression levels in whole-cell homogenate were not different between etoposide-treated and non-treated cells (Fig. 1A). However, the membrane localization of P-ERM was significantly increased in the presence of etoposide (Fig. 1B).

Effect of Etoposide on mRNA Level and Intracellular Localization of P-gp P-gp mRNA levels and protein expression levels in the whole-cell homogenate were unchanged by exposure to $100 \mu \mathrm{M}$ etoposide for $10 \mathrm{~min}$ (Figs. 2A, B). However, the membrane localization of P-gp in etoposide-treated cells was significantly greater than that in non-treated cells (Fig. 2C).

Effect of Etoposide on Efflux Rate of Rho123 in Caco-2 Cells When Caco-2 cells were stimulated with $100 \mu \mathrm{M}$ etoposide, the Rho123 efflux rate at $10 \mathrm{~min}$ was about two-fold higher than that of the control. This increase was completely suppressed by pretreatment with the CCK receptor inhibitor

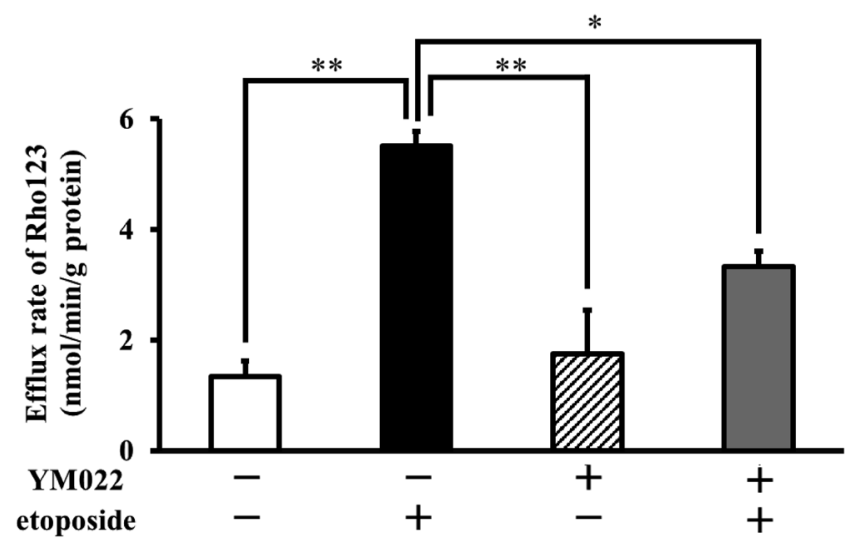

Fig. 3. Effect of Etoposide on the Efflux Rate of Rho123

Open and closed bars indicate control and etoposide-treated cells, respectively. Hatched and dotted bars indicate control and etoposide-treated cells incubated with YM022, respectively. Results are mean \pm S.E. $(n=3-6) * p<0.05, * * p<0.01 \mathrm{com}-$ pared with etoposide alone.

YM022. We confirmed that YM022 alone had no effect on the Rho123 efflux rate (Fig. 3).

Effect of Etoposide with or without YM022 on the Efflux Ratio of Rho123 in Caco-2 Cells The permeability coefficient of Rho123 in the basal-to-apical direction $\left(P_{\text {app, B to A }} \times 10^{6}\right)$ in etoposide-treated cells was significantly higher than those of the control, YM022-pretreated, and YM022-pretreated + etoposide-treated cells (Fig. 4A). In contrast, etoposide treatment did not alter the permeability coefficient in the apical-to-basal direction $\left(P_{\text {app, A to B }} \times 10^{6}\right)$ compared with the control, YM022-pretreated, or YM022- 
A
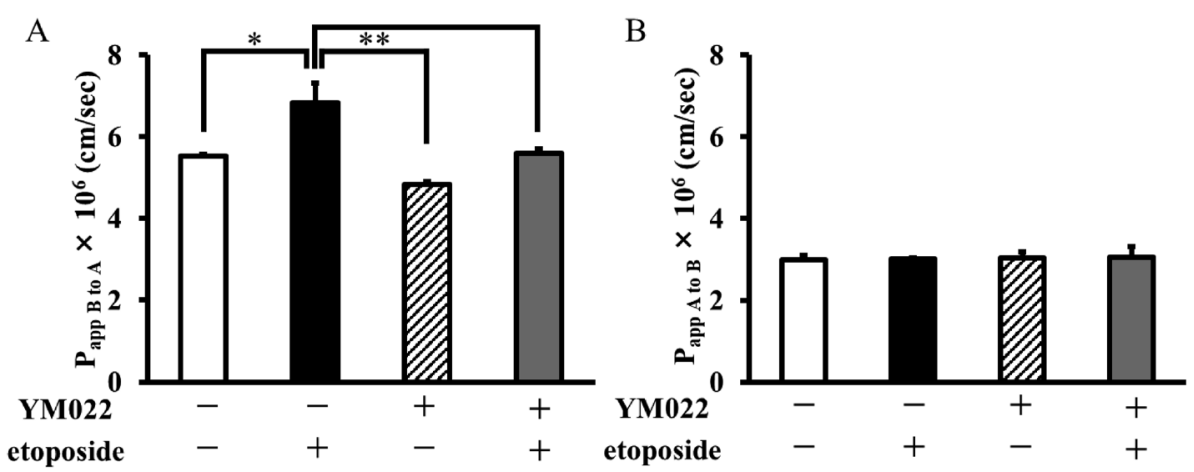

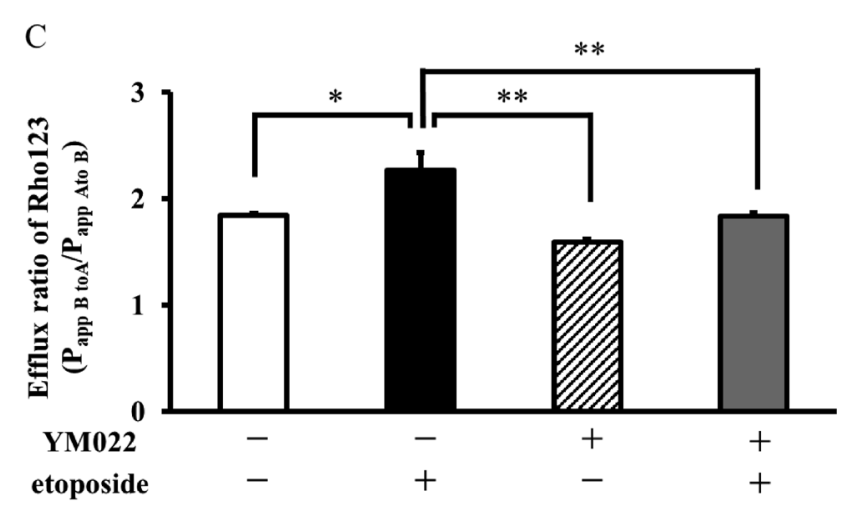

Fig. 4. Effect of Etoposide on Rho123 Transport in Caco-2 Cells

Open and closed bars indicate control and etoposide-treated cells, respectively. Hatched and dotted bars indicate control and etoposide-treated cells incubated with YM022, respectively. The permeability coefficients of Rho123 in the apical-to-basal direction $\left(P_{\text {app, A to B }}\right)$ and in the basal-to-apical direction $\left(P_{\text {app, B to A }}\right)$ were measured (A, B). The efflux ratio of Rho123 was calculated from these $P_{\text {app }}$ values (C). Open bars and oblique line bars indicate $P_{\text {app }}$ for the transport of Rho123 in the control and YM022-treated cells. Results are mean \pm S.E. $(n=3) * p<0.05, * * *<<0.01$ compared with etoposide alone.

pretreated + etoposide-treated cells (Fig. 4B). Therefore, the efflux ratio of Rho123 in cells treated with etoposide alone was significantly increased compared with that of the control cells, and YM022 significantly inhibited this increase in the efflux ratio of Rho123 (Fig. 4C).

\section{DISCUSSION}

Etoposide increased P-ERM levels in the plasma membrane fraction in Caco-2 cells at $10 \mathrm{~min}$, without affecting the levels in whole cells (Fig. 1). Moreover, P-gp mRNA and protein expression levels in whole cells were unchanged by etoposide treatment, while the P-gp level in the plasma membrane fraction was significantly increased. P-gp and ERM proteins in Caco-2 cells are expressed in the brush border membrane of the plasma membrane, not in the basolateral side membrane. ${ }^{16,17)}$ Therefore, our results indicate increased expression of P-gp protein in the brush border membrane. We previously showed that ERM proteins regulate P-gp membrane localization and transport function in several cell lines, by means of gene knockout and silencing studies. ${ }^{418-20)}$ Moreover, bitter substances such as PTC increase the membrane localization of P-gp concomitantly with an increase in P-ERM membrane expression. ${ }^{8)}$ Thus, the results of the present study are consistent with our previous findings, and indicate that etoposide induces P-ERM-mediated transfer of P-gp to the plasma membrane.

We next examined whether etoposide enhances P-gp transport function in Caco-2 cells. We found that etoposide exposure for $10 \mathrm{~min}$ significantly increased the efflux rate of Rho123 in Caco-2 cells (Fig. 3), while YM022, an inhibitor of cholecystokinin $(\mathrm{CCK})$ receptor, significantly suppressed this increase. However, not only the upregulation of P-gp-mediated efflux, but also the downregulation of an influx process could reduce the intracellular accumulation of Rho123. Hence, we evaluated bidirectional transport mediated by P-gp. Etoposide significantly increased the $P_{\text {app, B to A }}$ of Rhol23, a P-gp substrate, whereas $P_{\text {app, A to B was not different between control }}$ and etoposide-treated cells (Fig. 4). Consequently, the efflux ratio of Rho123 in etoposide-treated cells was significantly increased compared with control. Our previous studies have shown that various P-gp inhibitors such as verapamil, cyclosporine A and elaclidar reduce P-gp excretion of Rhol23 in P-gp expression cells. ${ }^{20-22)}$ Although it has not been sufficiently reported whether efflux transporters other than P-gp transport Rho123 in Caco-2 cells, it has been indicated that Rho123 is a useful substrate in evaluating the transport function of P-gp. ${ }^{23)}$ These reports support the contribution of P-gp to the transport of Rho123 in this study. Moreover, YM022 almost completely blocked the increase in $P_{\text {app, B to A, abrogat- }}$ ing the increase in the efflux ratio of Rho123. We confirmed that YM022 alone had little effect on the efflux rate, $P_{\text {app, A to B }}$ or the efflux ratio of Rho123. This result indicates that YM022 did not act as a substrate or direct inhibitor of P-gp. Therefore, it is considered that CCK receptor inhibition by YM022 might suppress the factor that upregulates P-gp, resulting in the suppression of the P-gp hyperactivity. These results indicated that P-gp function is upregulated by etoposide, and CCK receptor is involved in this upregulation, in agreement with our previous findings with PTC. ${ }^{8}$ Kobori et al. reported that repeated oral administration of etoposide to mice for several days increased the P-gp protein level in the membrane via an increase in radixin expression. ${ }^{11,12}$ This supports our conclu- 
sion that etoposide alters the ERM-mediated P-gp function in the gastrointestinal tract. However, Kobori et al. exposed the cells to etoposide for several days, whereas we exposed the cells for only $10 \mathrm{~min}$. It is reported that CCK can stimulate the CCK receptor and activate extracellular signal-regulated kinase (ERK) within 5 min. ${ }^{24,25)}$ Moreover, ERK activates Ras homolog gene family member A (RhoA), ${ }^{26)}$ which increases the membrane localization of P-ERM. ${ }^{27,28)}$ Although it remains unclear whether etoposide directly stimulated T2R or the CCK receptor as well as PTC, YM022 did suppress P-gp function enhanced by etoposide. Therefore, we consider that a brief treatment with etoposide is sufficient to stimulate bitter taste receptors and/or CCK receptors, leading to an increase of P-gp localization and transport function in the plasma membrane. Interestingly, when cells were treated with etoposide for $30 \mathrm{~min}$, Rho123 efflux by P-gp was inhibited (data not shown). Overall, these findings indicate that P-gp transport function is rapidly enhanced by extracellular etoposide, limiting the cellular uptake of etoposide. We have previously reported that CCK-induced hyperactivity of P-gp disappeared within $30 \mathrm{~min}^{8}{ }^{8}$ Therefore, it was considered that the increase in the membrane localization and function of P-gp by etoposide exposure was also expected to last for about $30 \mathrm{~min}$. Moreover, etoposide was accumulated intracellularly during its $30 \mathrm{~min}$ etoposide exposure, suggesting that its ability to act as a P-gp substrate ${ }^{29,30)}$ resulted in competitive inhibition of P-gp function. Our findings are consistent with the idea that bitter-tasting P-gp substrate drugs may rapidly enhance the function of P-gp to limit uptake into the body.

\section{CONCLUSION}

Etoposide, a P-gp substrate drug, rapidly enhances the function of P-gp in Caco-2 cells by increasing the localization of $\mathrm{P}$-gp on the gastrointestinal membrane via $\mathrm{CCK}$ receptormediated activation of ERM proteins.

Acknowledgments This work was supported by JSPS KAKENHI Grant Numbers 16K18956, 18K06793 and 19K16451 and Research Grants from the Takeda Science Foundation.

Conflict of Interest The authors declare no conflict of interest.

\section{REFERENCES}

1) Ogihara T, Mizoi K, Kamioka H, Yano K. Physiological roles of ERM proteins and transcriptional regulators in supporting membrane expression of efflux transporters as factors of drug resistance in cancer. Cancers, 12, 3352 (2020).

2) Yano K, Tomono T, Ogihara T. Advances in studies of Pglycoprotein and its expression regulators. Biol. Pharm. Bull., 41, 11-19 (2018).

3) Yano K, Seto S, Kamioka H, Mizoi K, Ogihara T. Testosterone and androstenedione are endogenous substrates of P-glycoprotein. Biochem. Biophys. Res. Commun., 520, 166-170 (2019).

4) Yano K, Tomono T, Sakai R, Kano T, Morimoto K, Kato Y, Ogihara T. Contribution of radixin to P-glycoprotein expression and transport activity in mouse small intestine in vivo. J. Pharm. Sci., 102, 2875-2881 (2013).

5) Morishita H, Okawa K, Ishii M, Mizoi K, Ito M, Arakawa H, Yano
K, Ogihara T. Gastrointestinal absorption of pimozide is enhanced by inhibition of P-glycoprotein. PLOS ONE, 15, e0232438 (2020).

6) Latorre R, Huynh J, Mazzoni M, Gupta A, Bonora E, Clavenzani P, Chang L, Mayer EA, De Giorgio R, Sternini C. Expression of the bitter taste receptor, T2R38, in enteroendocrine cells of the colonic mucosa of overweight/obese vs. lean subjects. PLOS ONE, 11, e0147468 (2016).

7) Yano K, Mita S, Morimoto K, Haraguchi T, Arakawa H, Yoshida M, Yamashita F, Uchida T, Ogihara T. Multiple linear regression analysis indicates association of P-glycoprotein substrate or inhibitor character with bitterness intensity, measured with a sensor. J. Pharm. Sci., 104, 2789-2794 (2015).

8) Yano K, Shimizu S, Tomono T, Ogihara T. Gastrointestinal hormone cholecystokinin increases P-glycoprotein membrane localization and transport activity in Caco-2 cells. J. Pharm. Sci., 106, 2650-2656 (2017).

9) Loo TW, Clarke DM. Nonylphenol ethoxylates, but not nonylphenol, are substrates of the human multidrug resistance P-glycoprotein. Biochem. Biophys. Res. Commun., 247, 478-480 (1998).

10) Silva R, Sousa E, Carmo H, Palmeira A, Barbosa DJ, Gameiro M, Pinto M, Bastos MdeL, Remiao F. Induction and activation of Pglycoprotein by dihydroxylated xanthones protect against the cytotoxicity of the P-glycoprotein substrate paraquat. Arch. Toxicol., 88, 937-951 (2014).

11) Kobori $T$, Harada $S$, Nakamoto $K$, Tokuyama S. Time-dependent changes in the activation of RhoA/ROCK and ERM/p-ERM in the increased expression of intestinal P-glycoprotein by repeated oral treatment with etoposide. J. Pharm. Sci., 102, 1670-1682 (2013).

12) Kobori $T$, Harada S, Nakamoto $K$, Tokuyama S. Changes in PtdIns(4,5)P2 induced by etoposide treatment modulates small intestinal P-Glycoprotein via radixin. Biol. Pharm. Bull., 37, 11241131 (2014).

13) Jeon TI, Seo YK, Osborne TF. Gut bitter taste receptor signaling induces ABCB1 through a mechanism involving CCK. Biochem. J., 438, 33-37 (2011).

14) Yano K, Todokoro I, Kamioka H, Tomono T, Ogihara T. Functional alterations of multidrug resistance-associated proteins 2 and 5, and breast cancer resistance protein upon Snail-induced epithelialmesenchymal transition in HCC827 cells. Biol. Pharm. Bull., 44, 103-111 (2021).

15) Tomono $T$, Yano K, Ogihara T. Snail-induced epithelial-tomesenchymal transition enhances $\mathrm{P}$-gp-mediated multidrug resistance in HCC827 cells. J. Pharm. Sci., 106, 2642-2649 (2017).

16) Meng Z, Le Marchand S, Agnani D, Szapacs M, Ellens H, Bentz J. Microvilli morphology can affect efflux active P-glycoprotein in confluent MDCKII-hMDR1-NKI and Caco-2 cell monolayers. Drug Metab. Dispos., 45, 145-151 (2017).

17) Nakano T, Sekine S, Ito K, Horie T. Ezrin regulates the expression of Mrp2/Abcc2 and Mdr1/Abcb1 along the rat small intestinal tract. Am. J. Physiol. Gastrointest. Liver Physiol., 305, G807-G817 (2013).

18) Yano K, Okabe C, Fujii K, Kato Y, Ogihara T. Regulation of breast cancer resistance protein and P-glycoprotein by ezrin, radixin and moesin in lung, intestinal and renal cancer cell lines. J. Pharm. Pharmacol., 72, 575-582 (2020).

19) Kamioka H, Tomono T, Fujita A, Onozato R, Iijima M, Tsuchida S, Arai T, Fujita Y, Zhang X, Yano K, Ogihara T. Moesin-mediated Pglycoprotein activation during snail-induced epithelial-mesenchymal transition in lung cancer cells. J. Pharm. Sci., 109, 2302-2308 (2020).

20) Yano K, Otsuka K, Kato Y, Kawabata H, Ohmori S, Arakawa H, Ogihara T. Different regulation of P-glycoprotein function between Caco-2 and Caki-1 cells by ezrin, radixin and moesin proteins. J. Pharm. Pharmacol., 68, 361-367 (2016).

21) Tomono T, Otsuka K, Yano K, Kanagawa M, Arakawa H, Ogihara H. Recommended daily dose of sesame lignans has no influence on 
oral absorption of P-glycoprotein substrates in rats. Biol. Pharm. Bull., 38, 1960-1963 (2015).

22) Tomono T, Machida T, Kamioka H, Shibasaki Y, Yano K, Ogihara T. Entinostat reverses P-glycoprotein activation in snail-overexpressing adenocarcinoma HCC827 cells. PLOS ONE, 13, e0200015 (2018).

23) Troutman MD, Thakker DR. Rhodamine 123 requires carriermediated influx for its activity as a P-glycoprotein substrate in Caco-2 cells. Pharm. Res., 20, 1192-1199 (2003).

24) Dabrowski A, Groblewski GE, Schafer C, Guan KL, Williams JA. Cholecystokinin and EGF activate a MAPK cascade by different mechanisms in rat pancreatic acinar cells. Am. J. Physiol., 273, C1472-C1479 (1997).

25) Piiper A, Elez R, You SJ, Kronenberger B, Loitsch S, Roche S, Zeuzem S. Cholecystokinin stimulates extracellular signal regulated kinase through activation of the epidermal growth factor receptor, Yes, and protein kinase C. Signal amplification at the level of Raf by activation of protein kinase Cepsilon. J. Biol. Chem., 278, 7065-7072 (2003).

26) Tong J, Li L, Ballermann B, Wang Z. Phosphorylation and acti- vation of RhoA by ERK in response to epidermal growth factor stimulation. PLOS ONE, 11, e0147103 (2016).

27) Matsui T, Maeda M, Doi Y, Yonemura S, Amano M, Kaibuchi K, Tsukita S, Tsukita S. Rho-kinase phosphorylates $\mathrm{COOH}$-terminal threonines of ezrin/radixin/moesin (ERM) proteins and regulates their head-to-tail association. J. Cell Biol., 140, 647-657 (1998).

28) Kobori T, Harada S, Nakamoto K, Tokuyama S. Activation of ERM-family proteins via RhoA-ROCK signaling increases intestinal P-gp expression and leads to attenuation of oral morphine analgesia. J. Pharm. Sci., 102, 1095-1105 (2013).

29) Borgnia MJ, Eytan GD, Assaraf YG. Competition of hydrophobic peptides, cytotoxic drugs, and chemosensitizers on a common Pglycoprotein pharmacophore as revealed by its ATPase activity. J. Biol. Chem., 271, 3163-3171 (1996).

30) Lagas JS, Fan L, Wagenaar E, Vlaming ML, van Tellingen O, Beijnen JH, Schinkel AH. P-Glycoprotein (P-gp/Abcb1), Abcc2, and Abcc3 determine the pharmacokinetics of etoposide. Clin. Cancer Res., 16, 130-140 (2010). 